\title{
Identification of FT family genes that respond to photoperiod, temperature and genotype in relation to flowering in cassava (Manihot esculenta, Crantz)
}

\author{
Oluwabusayo Sarah Adeyemo ${ }^{1} \cdot$ Peter T. Hyde ${ }^{1} \cdot \operatorname{Tim}_{\text {L. Setter }}^{1}$ (1)
}

Received: 14 August 2018 / Accepted: 3 December 2018 / Published online: 12 December 2018

(c) The Author(s) 2018

\begin{abstract}
Cassava is a starch-storing root crop that is an important source of dietary energy in tropical regions of the world. Genetic improvement of cassava by breeding is hindered by late flowering and sparse flower production in lines that are needed as parents. To advance understanding of regulatory mechanisms in cassava, this work sought to identify and characterize homologs of the FLOWERING LOCUS T (FT) gene. Ten members of the phosphatidylethanolamine-binding protein gene family, to which FT belongs, were obtained from the cassava genome database. Phylogenetic and sequence analysis of these proteins was used to identify two putative FT homologs which had amino acid sequences at key positions in accordance with those predicted for functional FTs. Expression of these ten genes was determined in mature leaves, immature leaves, flower buds, fibrous roots, storage roots and stem. The FT transcripts were expressed in mature leaves, as expected for their possible role in leaf-to-apical meristem signaling. In growth chamber studies, plants flowered earlier in long-day photoperiod than in short-day photoperiod. Expression studies indicated that while MeFT1 was expressed in leaves without a clear-cut photoperiod response, MeFT2 was expressed in a photoperiod-dependent manner, consistent with its involvement in photoperiodic control of flowering. In growth chambers that subjected plants to a range of temperatures from 22 to $34{ }^{\circ} \mathrm{C}$, flowering was delayed by warmer temperatures although MeFT1 and MeFT2 expression declined in only one genotype, indicating other factors regulate this response. The earliest flowering genotype, IBA980002, had high levels of MeFT1 and MeFT2 expression, suggesting that both homologs contribute to earliness of this genotype.
\end{abstract}

Keywords Flowering $\cdot$ FT $\cdot$ Photoperiod $\cdot$ Temperature $\cdot$ Phylogeny $\cdot$ Cassava

$\begin{array}{ll}\text { Abbreviations } \\ \text { FT } & \text { FLOWERING LOCUS T } \\ \text { MFT } & \text { MOTHER OF FT AND TFL1 } \\ \text { TFL1 } & \text { TERMINAL FLOWERI } \\ \text { Ebwana } & \text { Ebwanatereka } \\ \text { SD } & \text { Short day } \\ \text { LD } & \text { Long day } \\ \text { PEBP } & \text { Phosphatidylethanolamine-binding protein }\end{array}$

Communicated by Richard G. H. Immink.

Electronic supplementary material The online version of this article (https://doi.org/10.1007/s00497-018-00354-5) contains supplementary material, which is available to authorized users.

Tim L. Setter

TLS1@ cornell.edu

1 Section of Soil and Crop Sciences, School of Integrative Plant Science, Cornell University, Ithaca, NY, USA

\section{Introduction}

Cassava (Manihot esculenta, Crantz) is a crop with an edible high-starch root, which grows in tropical and subtropical regions of the world. It is one of the most important staplefood crops in tropical regions and is the world's fifth most important source of human dietary energy (FAO 2009). Flowering in cassava has received relatively little attention because in crop production systems it is propagated via stem cuttings, and the roots are harvested for consumption, rather than fruit or seed organs (Leihner 2002). However, cassava breeding is restricted because some genotypes with valuable agronomic characteristics flower extremely late and are nonsynchronous with other genotypes (Ceballos et al. 2017). Conventional breeding methods and the recently developed breeding system involving genomic selection hold promise, but to be successful they require relatively rapid and synchronous flowering to speed up the breeding cycle (Ceballos et al. 2015; Heffner et al. 2009; Wolfe et al. 2017). 
While flower induction is a vital developmental transition which has been studied in detail, only recently have the molecular regulatory factors been discovered (Zeevaart 2008). Floral induction is regulated by several environmental factors such as photoperiod and vernalization, which result in corresponding changes in the production of FT in leaves (Turck et al. 2008; Andres and Coupland 2012). The FLOWERING LOCUS T (FT) gene in Arabidopsis, and orthologs in all dicots and monocots studied to date, has been implicated to play a pivotal role in this floral transition. There is evidence that FT signaling plays a role in photoperiodic and developmental regulation in cassava and in closely related species in the Euphorbiaceae family. In Jatropha (Jatropha curcas L.), an FT homolog is expressed in all organs examined except young leaves and is thought to play a role in flower induction ( $\mathrm{Li}$ et al. 2014, 2015). Overexpression of the Jatropha homolog in Arabidopsis hastened flowering (Li et al. 2014). In leafy spurge (Euphorbia esula L.), long photoperiods stimulate accumulation of FT transcripts in a diurnal manner consistent with flower induction (Hao et al. 2015). In cassava, overexpression of Arabidopsis FT elicits extremely early flowering, indicating that cassava has the necessary signaling components to interact with and respond to the FT gene product (Adeyemo et al. 2017). In addition, FT overexpression increases the prolificacy of flower production and extends the longevity of flower development. Components of the circadian clock upstream of FT have also been characterized in cassava (Adeyemo et al. 2011). FT is a member of the phosphatidylethanolamine-binding protein (PEBP) family. FT signaling is antagonized by homologs of the Arabidopsis TFL1 gene, which are also members of the PEBP family ( $\mathrm{Li}$ et al. 2017; Lifschitz et al. 2014; Wickland and Hanzawa 2015). Studies indicate that TFL1 is expressed in the apical meristem or other locations where its gene product competes with the FT protein by competitive binding with flowering regulatory proteins (Baumann et al. 2015; Serrano-Mislata et al. 2016; Taoka et al. 2013). In addition to FT and TFL1, another part of the PEBP family includes homologs of MFT, which play various roles in plant species; for example, in Jatropha an MFT homolog is preferentially expressed in the seed where it regulates dormancy (Tao et al. 2014).

To advance our understanding of the molecular and physiological basis of flowering in cassava under different environmental conditions, we investigated the expression of cassava $F T$-like genes. In this study, our objectives were to: (1) characterize the phosphatidylethanolamine-binding protein (PEBP) family of genes in cassava and identify putative FT-like homolog(s), (2) compare the expression of these homologs in various tissues and (3) elucidate the expression of these homologs in various experimentally controlled photoperiod and temperature environments in relation to their effects on cassava flowering. These studies deepen our understanding of likely key players of flowering regulation and other important roles in cassava, thereby advancing the potential for applications in breeding programs.

\section{Results}

\section{Identification of cassava FT homologs and phylogenetic analysis}

To identify the cassava homolog(s) of Arabidopsis FLOWERING LOCUS T (FT), we searched the cassava genome sequence database (version 6.1, phytozome.jgi.doe.gov) using TBLASTN and the Arabidopsis FT amino acid coding sequence (AAF03936.1). Ten "hits" to the FT query with E values ranging from $2.8 \mathrm{e}-11$ to $2.7 \mathrm{e}-35$ were found. The two best matches to Arabidopsis FT (AtFT) had 77.6\% and $77.8 \%$ amino acid identity to the AtFT; six were top hits when the Arabidopsis TERMINAL FLOWERI (TFL1) amino acid sequence was used as the BLAST query, with identities between 72 and $77 \%$. We compared the encoded protein sequences of these ten genes with other known FT-related sequences from Arabidopsis and Glycine max, for which the FT/TFL gene family is well characterized, and J. curcas, which like cassava is a member of the Euphorbiaceae family (Supplementary Fig. 1). A multiple alignment of these amino acid residues revealed a high degree of conservation in the critical amino acid residues within members of this family of genes. The alignment of the cassava sequences with those in Arabidopsis and Jatropha is shown in Fig. 1. The cassava members have the conserved amino acids in positions 88 and 154 (numbered according to the Arabidopsis FT) which distinguish them as FT, TFL1, and MOTHER OF FT AND TFL1 (MFT) subfamily members (Wang et al. 2015).

Amino acid alignments were used to create a phylogenic tree by the neighbor-joining method in ClustalW (Fig. 2). Among the three major subfamilies, there were two cassava sequences in the FT clade (MeFT1, MeFT2), six in the TFL clade (MeTFL1, MeTFL2, MeTFL3 MeTFL4, MeTFL5 and MeTFL6) and two in the MFT clade (MeMFT1 and MeMFT2). Cassava FTs grouped closely with Jatropha FT, but slightly more distant from Arabidopsis FT and TSF. Among the two cassava MFTs, MeMFT1 was grouped closely with Arabidopsis and Jatropha sequences AtMFT and JcMFT1, respectively. The other cassava and Jatropha MFTs were intermediate between the Arabidopsis MFT and the FT and TFL clades. Among the TFLs, there appeared to be three subclades corresponding to AtTFL1 (MeTFL1, MeTFL2 and MeTFL3), AtATC (MeTFL4 and MeTFL5), and the more distant AtBFT (MeTFL6). 


\begin{tabular}{|c|c|c|}
\hline & & \\
\hline Selaginella PEBP & MGRSM----DPLVLGRVIGDVLDMFVPAVDMSVCY-GSKOVNNGCELKPSATQARPIVQVGSPHEEGALYTLVMVDPDAPSPSEPSMI & VHWIVADIPG \\
\hline AtMFT & MAASV----DPLVVGRVI GDVLDMF IPTANMSVYF-GPKHITNGCEIKPSTAVNPPKVNISG-HS-DELYTLVMTDPDAPSPSEPNMRA & NHWIVVDIPG \\
\hline JCMFT1 & MAASV----DPLVVGRVIGDVIDLFVPSVTMSVYY-GSKHVTNGCDVKPSTASNPPKLTISG--HPNDLYTLVMTDPDAPSPSEPSMRA & AHWVVADIPG \\
\hline MeMFT1 & MAASV----DPLVVGRVI GDVIDMF IPSVNMSVYY-GAKRVTNGCDVKPSLAVLPPQLTISG--LPHDLYTLVMTDPDAPS PSEPTMRE & VHWIVADIPG \\
\hline JCMFT2 & MARSL----EPLVVGKVI GEVLDMYNPVAEFTVHY-GSKQVANGCE IKPSVAAQKPHVHILGSRLS SDLYTLVMVDPDAPSPSEPKWRF & LLWIVVDIPE \\
\hline MeMFT2 & MARSL----EPLVVGKVI GEVLDMYNPVAEFTVHY-GSKOIANGCEIKPSAAAQKPHVHILGSRLSSDLYTLVMVDPDAPSPSEPKWRE & LHWIVVDIPE \\
\hline AtFT & MSINI---RDPLIVSRVVGDVLDPFNRSITLKVTY-GQREVTNGLDLRPSQVQNKPRVEIGG-EDLRNFYTLVMVDPDVPSPSNPHLRT & LHWLVTDIPA \\
\hline AtTSF & MSLSR---RDPLVVGSVVGDVLDPFTRLVSLKVTY-GHREVTNGLDLRPSQVLNKPIVEIGG-DDFRNFYTLVMVDPDVPSPSNPHQRE & LHWLVTDIPA. \\
\hline JCFT & MPRDQF--RDPLVVGRVI GDVLDPFTKSISLQVTYNHR-EVNNGCELKPSQVVNQPRVDIGG-DDLRTFYTLVMVDPDAPSPSDPNLRE & LHWLVTDIPA. \\
\hline MeFT1 & MPRD----RDPLAVGRVI GDVLDPF'TRSISLNITYNNRDHVTNGCELKPSQVVNQPRVDVGG-DDLRTFYTLVMVDPDAPSPSDPNLRA & LHWLVTDIPG \\
\hline MeFT2 & MFR------DPLAVGRVVGDVLDPFTRS I SLQVTYNNRDHVNNGCELKPSQVVNQPRVDIGG-DDLRTFYTLVMVDPDAPSPSDPNLRA & LHWLVTDIPA \\
\hline AtBFT & MSREI----EPLIVGRVIGDVLEMFNPSVTMRVTFNSNTIVSNGHELAPSLLLSKPRVEIGG-ODLRSFFTLIMMDPDAPSPSNPYMRA & LHWMVTDIPG \\
\hline MeTFL6 & MSRPME--P--LAVGRVVGEVVDSFTPSVRMVITYHSNKQVANGYEFMPSFVATRPRVEIGG-EDLRTAYTLIMTDPDAPSPSDPHLRA & LHWMVTDIPG \\
\hline JCTFL1C & MSRATE--PQPLTVGRI I GEVVDAFTPSVKMSVTYNPNRQVANGHELMPSVIAAKPRVEIGG-QDLRTSYTLIMTDPDAPS PSDPHLRA & IHWMVTDIPG \\
\hline AtATC & MARISS---DPLMV GRVI GDVVDNCLQAVKMTVTYNSDKQVYNGHELF'PSVVTYKPKVEVHGG-DMRSFFTLVMTDPDVPGPSDPYLRF & LHWIVTDIPG \\
\hline JCTFL1a & MAKVS---DPLVVGRVI GDVIDYFTPCMKMTVSYNSNKQVYNGHELF'PSAVTHKPKVEVQGA-DMRSFFTLVMTDPDVPGPSDPYQRF & LHWIVTDIPG \\
\hline MeTFL4 & MAKTST---DPLVVGRVI GDVIDYFTPVVKMTVSYNSNKQVYNGHELFPSAVTHKPKVEVQGG-DMRSFFTLVMTDPDVPGPSDPYLRD & LHWLVTDIPG \\
\hline MeTFL5 & MAKTS----DPLVVGRVIGDVIDYFSPSVKMTVSYCSNKQVYNGHELFPSAVKLKPKVEVQGG-DMRSFFTLIMTDPDVPGPSDPYLRF & LHWVVTDIPG \\
\hline AtTFL1 & MENMGTRVIEPLIMGRVVGDVLDFFTPTTKMNVSY-NKKQVSNGHELFPSSVSSKPRVEIHG-GDLRSFFTLVMIDPDVPGPSDPFLKA & LHWIVTNIPG \\
\hline MeTFL1 & MARII----EPLIVGGVIGDVLDPFLPAIKMSVSYN-SRQVHNGHELFPSTLVSKPKVEIQGA-DLRSFFTLVMIDPDVPGPSDPYLRA & LHWIVSNIPG \\
\hline JCTFL1b & MEKPV----DPLIVERVI GDVLDLFTPTIKMSVAYT-DRKVCNGHELYPSTIASKPKVAVEGD-DMRSFFTLVMTDPDVPGPSDPYLRF & LHWIVSDIPG \\
\hline MeTFL2 & MARII----EPLIVGRVI GDVLDSFTPSIKMSVSYS-NRNVYNGHEFYPSAVASKPKIEVQGG-DMRTFFTLVMTDPDVPGPSDPYLRF & LHWIVSDIPG \\
\hline MetFL3 & MARII----EPLIVGRVIGDVVDYFTPEVKMCVTYN-NRQVCNGYELYPSTAVAKPKVEVQGG-DMRSFFTLVMTDPDVPGPSDPYLRE & LHWVVSNIPG \\
\hline
\end{tabular}

\begin{tabular}{|c|c|c|c|c|c|}
\hline & & & 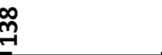 & 록 & \\
\hline Selaginella PEBP & GADASQ QRE I LQY I GPKPPT GIHRY I F'VVFRQMGPV--IML- & PPI & RNNESTRWFAO & EFLGLPVGAVYYNAQKE--PASRRRT-- & \\
\hline AtMFT & GTNPSRGKEILPYMEPRPPVGIHRYILVLFRQNSPV-GLMV- & QPA & SRANFSTRMFAG & FDLGLPVATVYFNAQKE--PASRRR--- & \\
\hline JCMFT1 & GTNPTK GKEILSYVGPRPPVGIHRYILVLFROKAAM- GVV- - & & SRANFNTRLFAA & HELGLPVATVYFNAQKE--PAAKRR--- & - \\
\hline MeMFT1 & GTNPTK $G K E I L A Y V S P R P P V G I H R Y I L V L F R Q R K A I-G M M--$ & esd & SRANFNTRMFAA & HELGLPVATVYFNAQKE--PAARRR--- & L \\
\hline JCMFT2 & GSDATKGHELVSYMGPQPPTGIHRYVFALFKOKGALMGRIQ- & PRD & RGNFNTRHFAA & OSGLGLPVAAVYFNSQKE--PAVKKR--- & 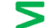 \\
\hline MeMFT2 & GSDATKGHELVPYMGPQPPTGIHRYVFALFKQK GALK GRSL- & GPD & RGNFSTRQFAA & DHGFGVPVAAVYFNSQKE--PAVKKR--- & \\
\hline AtFT & TTGTTFGNEIVCYENPSPTAGIHRVVF'ILF'RQLGR---QTV- & $A P C$ & RQNFNTREFAE & IINLGLPVAAVFYNCQRESGCGGRRL--- & \\
\hline AtTSF & TTGNAFGNEVVCYESPRPPS GIHRIVLVLFRQLGR---QTV- & & RQQFNTREFAE & IYNLGLPVAASYFNCQRENGCGGRRT--- & \\
\hline JCFT & TTGVTFGQEIVCYESPRPSLGIHRFVFILFRQLGR---QTV- & ped & RONFNTRDFAE & HNLGSPVAAVYFNCQRES GTGGRRR--- & \\
\hline MeFT1 & TTGASFGQEVVCYESPRPSVGIHRFVFILFRQLGR---QTV- & $A P S$ & RQNFNTRDFAE & YNLGLPVAAVYFNCQRES GSGGRRR--- & \\
\hline MeFT2 & TTAANFGQEVVCYESPRPSVGIHRFVFI LFRQLGR---QTV- & $A P d$ & RQNFNTRDFAE & YNLGLPVAAVYFNCQRETGSGGRRRGQ- & \\
\hline AtBFT & TTDASFGREIVRYETPKPVAGIHRYVFALFKQRGR---QAVK & $\mathrm{APE}$ & QRECFNTNAFSS & FGLSQPVAAVYFNAQRE--TAPRRRPSY & \\
\hline MeTFL6 & TTDASFGREVVSYETPKPVVGIHRYVFILFKQR $G R---Q T V-$ & & SDHFNTRRF'SE & NGLGLPVAAVYFNAQRE--TAARRR--- & \\
\hline JCTFL1C & TTDVSFGKEIVSYESPKPVVGIHRYVF'LLFKQRGR---QTV- & PPI & SRDYFNTRRF'AE & NGLGLPVAAVYFNAQRE--TAARRR--- & \\
\hline AtATC & TTDVSFGKEIIGYEMPRPNI GIHRFVYLLFKQTRR---GSVVS & SWPs & RDQFNTREFAH & ANDLGLPVAAVF FNCQRE--TAARRR--- & \\
\hline JcTFL1a & TTDATF GKEVVSYEMPRPNI $G I H R F V F I L F K Q K R R---Q-M V$ & TPI & SRDKFNTRKFAE & ANELGLPVAAVF FNAQRE--TAARRR--- & \\
\hline MeTFL4 & TTDATFGRELVSYEMPRPNI GIHRFVFLLFKOQRR---Q-TV & TPS & SRDKFNTRKF'AE & ANGLGLPVAAVFFNAQRE--TAARRR--- & \\
\hline MeTFL5 & TTDATFGREVVSYEMPRPNI GIHRFVFLLFKQQRR---QAIVS & PrS & SREKFNTRKFAE & ANGLLPVAAVFFNAQRE--TAARRR--- & \\
\hline AtTFL1 & TTDATFGKEVVSYELPRPSI GIHRF'VFLFRQKQR---RVI & NI & SRDHFNTRKFAV & ADLGLPVAAVFFNAQRE--TAARKR--- & \\
\hline MeTFL1 & TTDSTFGKEVASYEIPKPNI GIHRF'V F'VLKOKRR---QIIS & PPS & SRDNFNTRRFAT & ANLGLPVAAVFFNAQRE--TAARRR--- & \\
\hline JCTFL1b & TTDATF GKEIVSYEIPRPNI GIHRFVFVLFKOKKR---SQId & PPi & SRDNFNTRNFAA & ANELGLPVAAVYFNAQRE--TAARRR--- & \\
\hline MeTFL2 & TTDATFGREVVSYEIPRPNI GIHRFVFVLFKOKRR---HTIN & -prs & SRDHFSTRNFAA & ANDLGLPVAAVYFNAQRE--TAARRR--- & \\
\hline MeTFL3 & TTDATFGREVVSYEIPRPNI GIHRFVYLLFROKRR---QTIN & PPI & SRDNF STRNFAA & ENDLGPPVAAVYFNAQRE--TAARRR--- & \\
\hline
\end{tabular}

Fig. 1 Alignment and comparison of cassava sequences with Arabidopsis and Jatropha sequences of the PEBP family. Peptide sequences are grouped into their apparent relationships to Arabidopsis MFT, FT and TFL1 proteins. Marked positions are numbered according to AtFT. Shown are sequences from Selaginella moellendorffii (XP_002992458.1); Arabidopsis: AtMFT (NP_173250.1), AtBFT (NP_201010.1), AtFT (NP_176726.1), AtTSF (NP_193770.1), AtTFL1 (NP_196004.1), AtATC (NP_180324.1); Jatropha (Li et al. 2014): JcFT (KF113881), JcTFL1a (KF944349), JcT-

\section{Tissue-specific expression patterns of cassava PEBP genes}

To explore the prospects for various functions of the cassava PEBP genes, we examined their transcript expression in different tissues of the early-flowering genotype IBA980002 using primers shown in Supplementary Table 1. MeFT1 and MeFT2 were highly expressed in mature leaves, the presumed tissue that generates the flower induction signal (Fig. 3, top panels). MeFT1 and MeFT2 were also expressed in most of the other organs, except the storage root. MeFT2 expression was absent in
FL1b (KF944350), JcTFL1c (KF944351), JcMFT1 (KF944348) and JcMFT2 (KF944352); and cassava (from phytozome.jgi. doe.gov database): MeFT1 (Manes.12G001600.1), MeFT2 (Manes.13G000800.1), MeTFL1 (Manes.09G056300.1), MeTFL2 (Manes.13G011900.1), MeTFL3 (Manes.08G024500.1), MeTFL4 (Manes.04G004700.1), MeTFL5 (Manes.11G161100.1), MeTFL6 (Manes.14G027800.1), MeMFT1 (Manes.06G008200.1) and MeMFT2 (Manes.16G019600.1)

young leaves. In contrast to MeFT1 and MeFT2, there was negligible expression of both MeMFT1 and MeMFT2 in mature leaves (Fig. 3, middle panels). MeMFT1 expression was high in the growing tissues of young leaves and flower buds, while MeMFT2 was high in fibrous roots and stems. Also in contrast to the MeFTs, expression of all of the MeTFLs was negligible in mature leaf tissue, except for MeTFL6 (Fig. 3, bottom panels). There were no clearcut patterns of tissue-specific expression among the MeTFLs. All tissues had expression of at least one, and often several, of the MeTFLs. 
Fig. 2 Phylogenetic tree of FT-like and PEBP-related peptides in cassava (MeFT1, MeFT2, MeTFL1, MeTFL2, MeTFL3, MeTFL4, MeTFL5, MeTFL6, MeMFT1, MeMFT2), Arabidopsis (AtMFT, AtBFT, AtFT, AtTSF, AtTFL1, AtATC) and Jatropha (JcFT, JcTFL1a, JcTFL1b, JcTFL1c, JcMFT1 and JcMFT2). Sequences were aligned with ClustalW, and the results are displayed graphically using TreeView

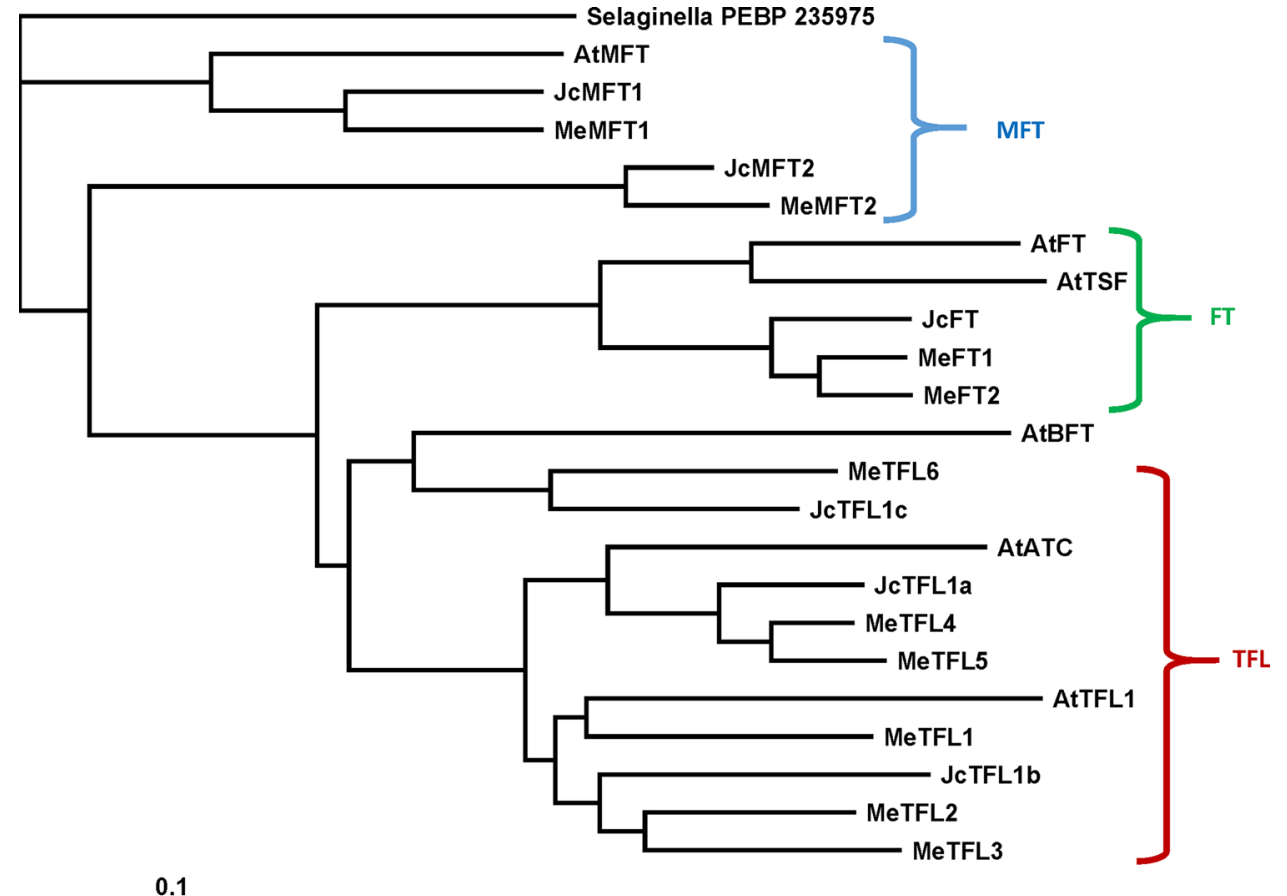

\section{Response of flowering and FT-like transcripts to photoperiod}

To elucidate the involvement of cassava FT-like genes in regulating flowering under varying photoperiod conditions, we tested cassava genotypes with two photoperiod treatments in growth chambers: 10-h illuminated/14-h dark, versus 14-h illuminated with $10 \mathrm{~h}$ of full illumination at high photon flux density followed by $4 \mathrm{~h}$ of dim light/10-h darkness (10-h vs. 14-h daylength). The genotypes tested represented a wide range of behaviors. One of the genotypes, IBA980002, flowered much earlier than the other genotypes such that all plants had advanced to the second tier of flowering during the period of observation, while none of the Ebwanatereka plants flowered during this period (Table 1). Flower appearance was hastened by long days in all of the genotypes that flowered. Long days increased the fraction of plants that flowered within the period of observation, and among those that flowered, it decreased the average age at flowering.

Expression of MeFT1 and MeFT2 transcripts was measured in mature leaves of the five genotypes under SD and LD conditions of the growth chambers. Across the full range of genotypes tested and daylengths imposed, there was no clear relationship between flower induction (Table 1) and MeFT1 expression (Fig. 4, left panel). The highest MeFT1 expression was in IBA980002, the early-flowering line, but expression was also quite high in Ebwanatereka, which failed to flower. Only TMEB419 responded to LD photoperiod with higher MeFT1 expression, corresponding to flower induction with this treatment. In contrast, for all five genotypes, MeFT2 transcript was expressed at low levels in short days whereas its expression in long days was substantially and significantly $(P \leq 0.05)$ higher (Fig. 4). Hence, MeFT2 expression was generally well correlated with the effect of long days in hastening flowering (Table 1). Even Ebwanatereka, which did not flower during the observation period, had substantially higher expression of MeFT2 in LD than in SD conditions. In the SD environment, only IBA980002, the early-flowering line, expressed MeFT2 at moderate levels, and it had the highest expression in long days.

\section{Response of Flowering and FT-like Transcripts to Temperature}

To examine the effect of temperature on flower induction, cassava plants were grown in matched growth chambers at day temperatures of $22{ }^{\circ} \mathrm{C}, 28{ }^{\circ} \mathrm{C}$ and $34{ }^{\circ} \mathrm{C}$, and night temperatures $3{ }^{\circ} \mathrm{C}$ lower in each case. The fraction of plants that flowered and the average age of plants when flowering took place were compared for two contrasting genotypes at three successive tiers of flowering (Table 2). In the early-flowering line, IBA980002, all of the plants had three tiers of flowering at 22 and $28^{\circ} \mathrm{C}$ day temperatures. However, none of the plants flowered at $34{ }^{\circ} \mathrm{C}$. First-tier flowering in the 22 and $28{ }^{\circ} \mathrm{C}$ treatments was between 75 and $82 \%$. The Cox proportional hazard test (Cox 1972), which takes into account both the fraction of plants that flowered and the age at flowering, indicated that the 22 and $28{ }^{\circ} \mathrm{C}$ treatments were not discernibly different, whereas plants in the $34{ }^{\circ} \mathrm{C}$ treatment were significantly 

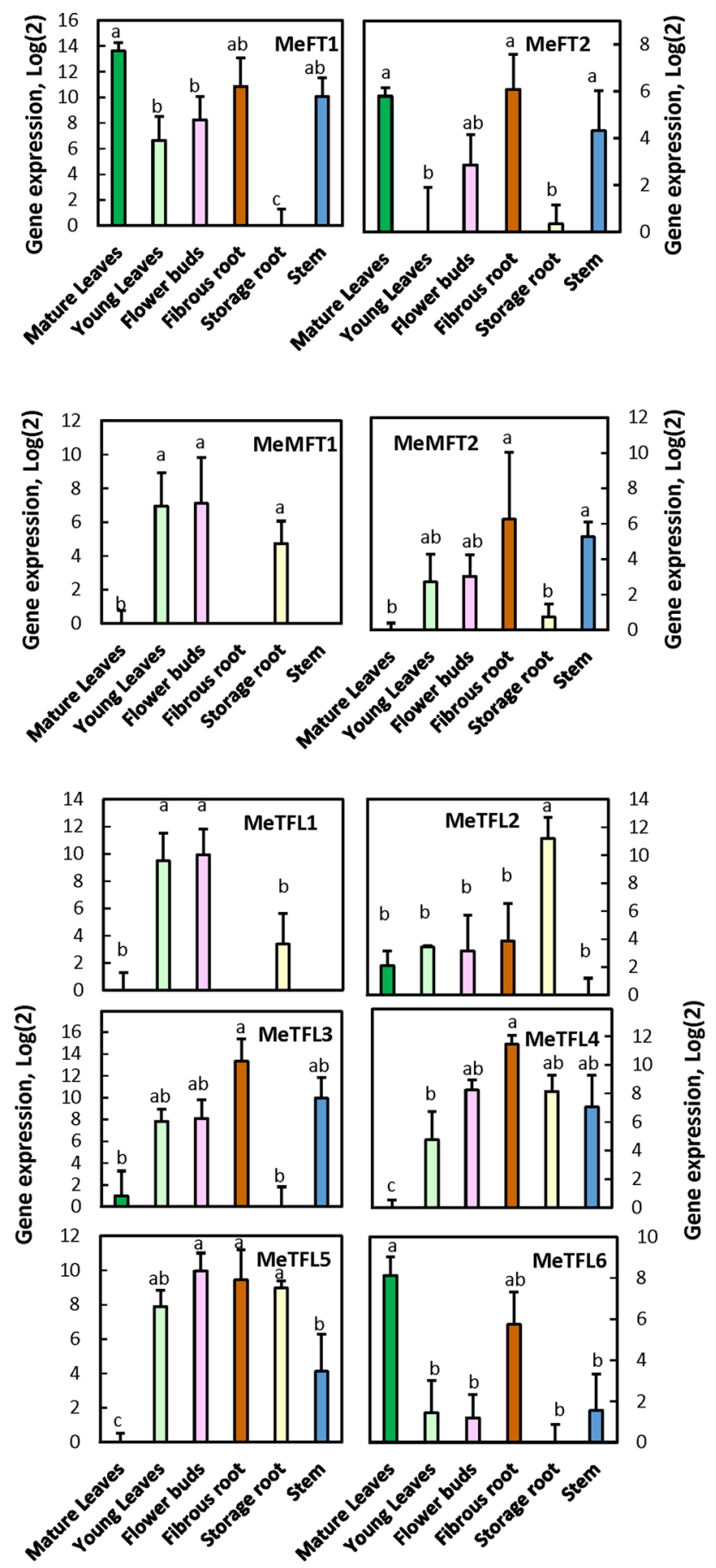

Table 1 Response of flowering in cassava to photoperiod treatments with the indicated daylengths

\begin{tabular}{llccl}
\hline Genotype & Daylength (h) & Tier & $\begin{array}{l}\text { Fraction } \\
\text { flowered } \\
(\%)\end{array}$ & $\begin{array}{l}\text { Age to } \\
\text { flowering } \\
\text { (days) }\end{array}$ \\
\hline IBA980002 & 10 & 2nd & 0 & $\mathrm{n} / \mathrm{a}^{\mathrm{b}}$ \\
IBA980002 & 14 & $2 \mathrm{nd}$ & $100^{*}$ & $145^{*}$ \\
Nase 14 & 10 & $1 \mathrm{st}$ & 0 & $\mathrm{n} / \mathrm{a}$ \\
Nase 14 & 14 & $1 \mathrm{st}^{\mathrm{b}}$ & $67^{*}$ & $172^{*}$ \\
Nase 3 & 10 & $1 \mathrm{st}$ & 0 & $\mathrm{n} / \mathrm{a}$ \\
Nase 3 & 14 & $1 \mathrm{st}$ & $33^{*}$ & $216^{*}$ \\
TMEB419 & 10 & $1 \mathrm{st}$ & 0 & $\mathrm{n} / \mathrm{a}$ \\
TMEB419 & 14 & $1^{\mathrm{st}}$ & $50^{*}$ & $159^{*}$ \\
Ebwanatereka & 10 & $1 \mathrm{st}$ & 0 & $\mathrm{n} / \mathrm{a}$ \\
Ebwanatereka & 14 & $1 \mathrm{st}$ & 0 & $\mathrm{n} / \mathrm{a}$ \\
\hline
\end{tabular}

Shown are the proportion of plants that flowered at the indicated branch points (tier-1 or tier-2), and, for the plants that flowered, their average age at flowering (time from propagation of stem cuttings to flowering)

*Significant $(P \leq 0.05)$ effect of daylength within paired genotypes

${ }^{a}$ Represents flowering at the tier most closely corresponding to the sampling date. For Batch 1, it is first tier, and for Batch 2, it is second tier

${ }^{\mathrm{b}}$ Not applicable

$(P \leq 0.05)$ different at all three tiers. In the late-flowering genotype, TMEB 419 , the $22{ }^{\circ} \mathrm{C}$ treatment had significantly $(P \leq 0.05)$ higher percent flowering and average age of flowering than the two warmer treatments. At $22^{\circ} \mathrm{C}$, this genotype flowered on the first tier at $145 \mathrm{~d}$ after planting and did not flower subsequently. There were no flowers produced in the warmer treatments at 28 and $34{ }^{\circ} \mathrm{C}$. Hence, for both genotypes, flowering was better at cool than warm temperatures.

The expression levels of both MeFT1 and MeFT2 transcripts were higher in the early-flowering line, IBA980002, than in the late-flowering line, TMEB419 (Figs. 4, 5). However, there was not a clear-cut relationship between the temperature response of flowering and the level of transcript expression (Fig. 5). In IBA980002, the trend was increasing MeFT1 and MeFT2 expression with increased temperature, which was counter to the trend of poorer flowering at increased temperature. Only MeFT2 in TMEB419 tended to have lower expression at warm temperature, which corresponded with the lack of flowering at warm temperature.

Fig. 3 Expression of cassava FT-like transcripts (top panel), MFTlike transcripts (middle panel) and TFL1-like transcripts (bottom panel) in various organs of cassava genotype IBA980002. Transcripts were analyzed by quantitative RT-PCR using extracts from mature leaves, unexpanded young leaves, flower buds, fibrous roots, storage roots and stems. Further details are given in the Materials and methods section. Plants were grown in LD photoperiod at $28 / 25{ }^{\circ} \mathrm{C}$ day/ night temperature. Shown are the average and SEM of 4 biological replicates of $\log _{2}$ (relative expression) for each transcript. Letters above error bars indicate significant differences $(P \leq 0.05)$ when letters differ

\section{Discussion}

\section{Identification of cassava FT's}

In this study, we identified ten members of the PEBP gene family in cassava and compared them to homologs in 


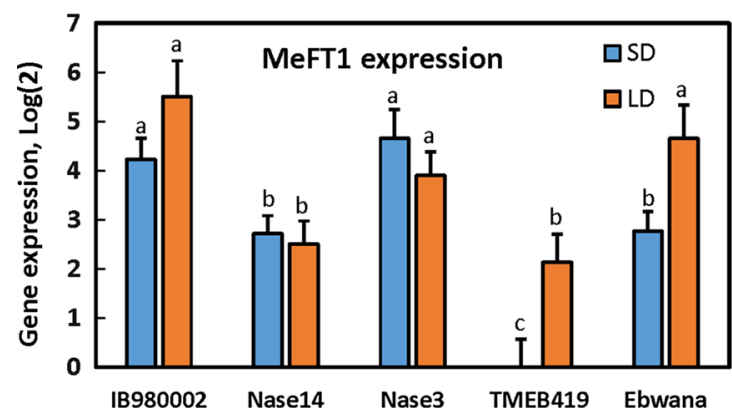

Fig. 4 Expression of cassava MeFT1 (left panel) and MeFT2 (right panel) in response to short day (SD 10-h photoperiod) and long day (LD 14-h photoperiod). Leaf samples were sampled at the end of the light period, and transcripts were analyzed by quantitative RT-PCR.

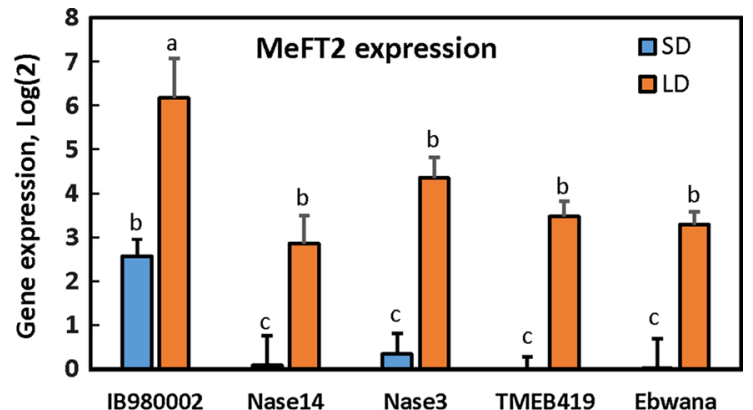

Shown are the average and SEM of 6 biological replicates of $\log _{2}$ (relative expression) for each transcript. Letters above error bars indicate significant differences $(P \leq 0.05)$ when letters differ

Table 2 Response of flowering in cassava genotypes to temperature treatments

\begin{tabular}{|c|c|c|c|c|c|c|c|c|c|c|}
\hline \multirow[t]{2}{*}{ Genotype } & \multirow{2}{*}{$\begin{array}{l}\text { Temperature, } \\
\text { day/night }\left({ }^{\circ} \mathrm{C}\right)\end{array}$} & \multicolumn{3}{|l|}{ Tier 1} & \multicolumn{3}{|l|}{ Tier 2} & \multicolumn{3}{|l|}{ Tier 3} \\
\hline & & $\begin{array}{l}\text { Fraction } \\
\text { flowered } \\
(\%)\end{array}$ & $\begin{array}{l}\text { Age to } \\
\text { flowering } \\
\text { (days) }\end{array}$ & Cox test & $\begin{array}{l}\text { Fraction } \\
\text { flowered } \\
(\%)\end{array}$ & $\begin{array}{l}\text { Age to } \\
\text { flowering } \\
\text { (days) }\end{array}$ & Cox test & $\begin{array}{l}\text { Fraction } \\
\text { flowered } \\
(\%)\end{array}$ & $\begin{array}{l}\text { Age to } \\
\text { flowering } \\
\text { (days) }\end{array}$ & Cox test \\
\hline IBA980002 & $22 / 19$ & 100 & 75 & $a^{*}$ & 100 & 123 & $\mathrm{a}$ & 100 & 165 & $\mathrm{a}$ \\
\hline IBA980002 & $28 / 25$ & 100 & 82 & a & 100 & 117 & $\mathrm{a}$ & 100 & 164 & $\mathrm{a}$ \\
\hline IBA980002 & $34 / 31$ & 0 & $\mathrm{n} / \mathrm{a}$ & $\mathrm{b}$ & 0 & $\mathrm{n} / \mathrm{a}$ & $\mathrm{b}$ & 0 & $\mathrm{n} / \mathrm{a}$ & $\mathrm{b}$ \\
\hline TMEB419 & $22 / 19$ & 75 & 145 & $\mathrm{~b}$ & 0 & $\mathrm{n} / \mathrm{a}$ & $\mathrm{b}$ & 0 & $\mathrm{n} / \mathrm{a}$ & $\mathrm{b}$ \\
\hline TMEB419 & $28 / 25$ & 0 & $\mathrm{n} / \mathrm{a}$ & $\mathrm{b}$ & 0 & $\mathrm{n} / \mathrm{a}$ & $\mathrm{b}$ & 0 & $\mathrm{n} / \mathrm{a}$ & $\mathrm{b}$ \\
\hline TMEB419 & $34 / 31$ & 0 & $\mathrm{n} / \mathrm{a}$ & $\mathrm{b}$ & 0 & $\mathrm{n} / \mathrm{a}$ & $\mathrm{b}$ & 0 & $\mathrm{n} / \mathrm{a}$ & $\mathrm{b}$ \\
\hline
\end{tabular}

Shown are the proportion of plants that flowered at branch points for tier-1, tier- 2 and tier-3 of fork-type branching, and for those that flowered, their average age at flowering (time from propagation of stem cuttings to flowering). Cox Proportional Hazard test results are shown for each tier *Values within a column with different letters are significantly different $(P \leq 0.05)$ based on the Cox proportional hazard multiple comparison test

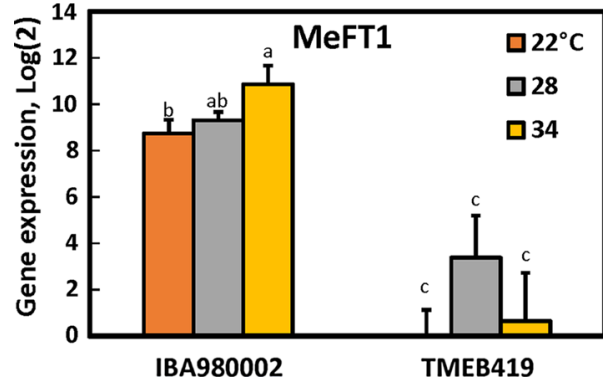

Fig. 5 Expression of cassava MeFT1 (left panel) and MeFT2 (right panel) in two cassava genotypes (IBA980002 and TMEB419) in response to daytime growth temperatures of 22,28 and $34{ }^{\circ} \mathrm{C}$ (night temperature $3{ }^{\circ} \mathrm{C}$ cooler in each case). Shown are the average and

Arabidopsis and J. curcas, a closely related species (Figs. 1, 2). Our goal was to identify the likely cassava FT(s) for leaf-to-apical meristem signaling. Consistent with previous findings in most other species (Wang et al. 2015), at amino acid position 85 (numbered according to Arabidopsis FT), cassava putative FTs had a tyrosine (Y), whereas cassava

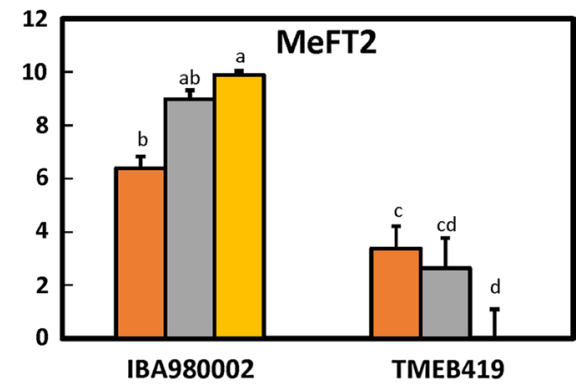

SEM of 4 biological replicates of $\log _{2}$ (relative expression) for each transcript. Letters above error bars indicate significant differences $(P \leq 0.05)$ when letters differ

TFL1s all had histidine (H) at this position, and MFTs had tryptophan (W) (Fig. 1). The His residue has been shown via functional conversion studies to repress flowering while Tyr amino acid residue activates flowering (Hanzawa et al. 2005). Another defining position, residue 151 (AtFT numbering), has also been shown to convert these proteins from 
flowering induction to repression (Wang et al. 2015); in cassava putative FT's, this residue was leucine (L), while cassava putative TFL1s all had glutamate (E), in accordance with previous findings (Wang et al. 2015) (Fig. 1). Cassava FT homologs were also consistent with flower induction at two other conserved sites that distinguish flower induction from repressor function (Wickland and Hanzawa 2015). At position 134, cassava FTs contain tyrosine (Y), and at position 138, cassava FTs contain tryptophan (W), consistent with the putative flower inductive function of these proteins, whereas cassava putative TFL1s contained serine (S) at position 138, consistent with a repressor function (Wickland and Hanzawa 2015).

Among the tissues analyzed, MeFT1 and MeFT2 expression was highest in mature leaves, but lower in flowers (Fig. 3), as expected for a florigen-expressing gene (Chen et al. 2018). In Arabidopsis, FT is highly expressed in the leaves, in response to photoperiodic perception occurring in this organ. However, in surveys of PEBP-family transcripts in other species, tissue-specific patterns alone are difficult to interpret with respect to function (Wang et al. 2015). In Jatropha JcFT, expression was highest in female flowers, but low in leaves (Li et al. 2015). Neither of the cassava MFT transcripts were expressed in mature leaves, and among the six cassava TFLs, only MeTFL6 was significantly $(P \leq 0.05)$ expressed in mature leaves. The role of the Arabidopsis TFL1 in repressing flowering involves its expression in the apical meristem, as has been found several species (Esumi et al. 2010; Hou and Yang 2009; Serrano-Mislata et al. 2016; Turck et al. 2008). All of the cassava TFLs, except MeTFL6, were significantly $(P \leq 0.05)$ expressed in young flowers and flower buds, in the approximate region of the apical tissue.

\section{Potential roles of FTs in photoperiod and temperature response}

The expression pattern of MeFT2 in response to photoperiod matched that of flowering and supported the hypothesis that it plays a role in photoperiod signal development in the leaf (Fig. 4). Tissue samples for this analysis were obtained at the end of the daily light period in each treatment. In LD plants exposed to LD conditions, functional FTs are highly expressed in leaves at this time-of-day to generate a signal that elicits flowering (Andres and Coupland 2012; Turck et al. 2008). In contrast, the genotype Ebwanatereka exhibited a substantial increase in MeFT2 expression in response to $\mathrm{LD}$ even though flowering was not observed. However, given that this is a late-flowering line, it is possible that a longer period of observation would have revealed flowering in response to the LD photoperiod. MeFT1 expression in most of the genotypes did not respond to photoperiod, and calls into question its possible role in flowering. Only in TMEB419 did MeFT1 expression respond to photoperiod in a pattern consistent with LD flowering response. Cassava's two FTs, with MeFT2 expression more clearly involved in photoperiod response, might be analogous to Arabidopsis where TSF and FT are close homologs, which play overlapping roles in the promotion of flowering, with FT playing the dominant role (Jin et al. 2015). Also, in soybean, GmFT2a is strictly regulated by photoperiodic changes from SD to $\mathrm{LD}$, whereas the response of GmFT5a expression is gradual and low even after transfer to LD (Nan et al. 2014). In sugar beets, BvFT2 is the functional FT homolog, with negligible expression under SD conditions and gradually increasing expression in mature leaves exposed to LD, which correlates with the initiation of flowering, while $\mathrm{BvFT1}$ represses floral development and its expression is promoted by SDs and inhibited by exposure to cold temperature (Pin et al. 2010; Pin and Nilsson 2012). Indeed, there are several examples in plant species where multiple FT homologs have functionally differentiated responses to environmental stimuli, and with respect to floral induction versus repression (Wickland and Hanzawa 2015).

As in many plant species, flowering in cassava was delayed when temperature was warmed in the moderate range from 22 to $34{ }^{\circ} \mathrm{C}$ (Yan and Wallace 1996) (Table 2). Studies in many species have indicated that in the moderate range of temperatures, where vernalization and thermal stress are not involved, warmer temperatures repress flowering and increase days-to-flower (Paton 1968; Yan and Wallace 1996). Cassava is well adapted to growth in hot climates, and its shoot and storage-root yield is highest at daytime temperatures of $35-40{ }^{\circ} \mathrm{C}$ (Jarvis et al. 2012). The expression of MeFT2 decreased with increasing temperature in TMEB419 in accordance with delayed flowering; however, in IBA980002 the temperature responses of both MeFT1 and MeFT2 were counter to the observed delay in flowering at warmer temperatures. Studies in some species have demonstrated FT expression levels that correlate with temperature effects on flower induction, including studies in Fragaria $\times$ ananassa (Nakano et al. 2015b), Narcissus tazetta (Noy-Porat et al. 2013), chrysanthemum (Nakano et al. 2015a), citrus (Chica and Albrigo 2013; Fukuda et al. 2011). Thus, it appears that in cassava additional factors were responsible for the observed effect of temperature on flowering, at least for IBA980002. Several mechanisms of temperature effects on flowering have been identified, including temperature-sensitive Phytochrome-B interactions (Jung et al. 2016), PIF4/PIF5 interactions (Thines et al. 2014) and FLM/SVP interactions (Melzer 2017; Pose et al. 2013). While PhyB and PIF mechanisms act upstream of FT expression and would be expected to affect FT levels in leaves, FLM/SVP interactions may act downstream, such as in the apical meristem. Temperature-regulated flowering 
could thus involve changes in such factors without affecting FT levels in leaves.

\section{Genotypic differences in FT expression}

Cassava genotypes differed in flowering: IBA980002 flowered considerably earlier and initiated inflorescences more frequently at successive tiers; Nase 3, Nase 14, and TMEB419 flowered later; and Ebwanatereka failed to flower during the period of observation (Tables 1, 2). Both MeFT1 and MeFT2 expressions were highest in IBA980002 compared to the others in LD and SD conditions and in at all three temperatures (Figs. 4, 5). However, differences in flowering between the other four genotypes were not associated with expression levels of the FT transcripts. This suggests that genotypic differences in other components of the regulatory system for flower development are likely responsible. Indeed, analyses of flowering time in diversity trials have identified large numbers of novel genetic loci, relative to known flowering genes (Buckler et al. 2009; Li et al. 2010).

\section{Conclusions}

We have analyzed the PEBP family of genes in cassava and identified two putative FT homologs whose amino acid sequence at key positions is in accordance with functional FTs. These FTs were expressed in mature leaves, as expected for their possible role in leaf-to-apical meristem signaling. Expression studies indicated that while MeFT1 is expressed in leaves without a clear-cut photoperiod response, MeFT2 is expressed in a photoperiod-dependent manner, and is a strong candidate to explain photoperiodic control of signaling. The earliest flowering genotype, IBA980002, had high MeFT1 and MeFT2 expression, suggesting that both homologs contribute to earliness. The genotype-dependent temperature response of flowering time and expression of these FTs suggests that other signaling factors downstream of FT are likely involved.

\section{Materials and methods}

\section{Plant materials}

Cassava plantlets were obtained as tissue culture explants; genotypes IBA980002 (also known as TMS I980002) and TMEB419 were obtained from the International Institute of Tropical Agriculture (IITA), Ibadan, Nigeria; genotypes Nase 3, Nase 14 and Ebwanatereka (abbreviation: Ebwana) were obtained from the National Crops Resources Research Institute (NaCRRI), Namulonge, Uganda. These genotypes are described by Bredeson et al. (2016). Seedlings were grown to full-size plants in the greenhouse and vegetatively propagated with stem cuttings for at least three growth cycles in horticultural rooting media of peat moss/vermiculite/perlite (1:1:1, by volume) to which was added by mixing: $2.2 \%(\mathrm{w} / \mathrm{v})$ dolomitic limestone, $0.1 \%(\mathrm{w} / \mathrm{v})$ wetting agent (AquaGro 2000G, Aquatrols, Paulsboro, NJ 08066, USA), and 2.2\% (w/v) 10-5-10 Jacks Pro Media mix plus III (J.R. Peters, Inc., Allentown, Pennsylvania, USA). To initiate experiments in growth chambers, stem segments (stakes $1.5-2.5 \mathrm{~cm}$ dia, $10-15 \mathrm{~cm}$ long) from the bottom $1 \mathrm{~m}$ of 6-month-old plants were cut and planted into 11-L plastic pots. After 2-week growth in the greenhouse, sprouted seedlings were moved to growth chambers as described below.

\section{Growth conditions and environmental treatments}

Growth chambers for the photoperiod experiment were Scherer, model CEL 511-38 walk-in rooms $(130 \times 260 \times 200 \mathrm{~cm}$ [ht.] $)$ with illumination by Philips cool white $(4100 \mathrm{~K})$ fluorescent lamps. The photoperiod experiment had two light regimes: short day (SD) with $10 \mathrm{~h}$ of $400 \mu \mathrm{mol}$ photons $(400-700 \mathrm{~nm})$ of photosynthetically active radiation [PAR] $\mathrm{m}^{-2} \mathrm{~s}^{-1}$; and long day (LD) with $10 \mathrm{~h}$ of $400 \mu \mathrm{mol}$ photons $(400-700 \mathrm{~nm}) \mathrm{m}^{-2} \mathrm{~s}^{-1}$ in light flux density with an additional $4 \mathrm{~h}$ photoperiod extension at $10 \mu \mathrm{mol} \mathrm{m}^{-2} \mathrm{~s}^{-1}$. The trials were conducted at two temperature regimens: a daytime temperature of $30^{\circ} \mathrm{C}$ and a night temperature of $25^{\circ} \mathrm{C}$ (Batch 1) and at a daytime temperature of $25^{\circ} \mathrm{C}$ and a night temperature of $20^{\circ} \mathrm{C}$ (Batch 2).

Growth chambers for the studies on temperature and plant organs were walk-in growth rooms $(135 \times 245 \times 180 \mathrm{~cm}$ [ht.]) with ten $400 \mathrm{~W}$ high pressure sodium and ten $400 \mathrm{~W}$ metal halide lamps, providing $600 \mu \mathrm{mol}$ photons (400-700 nm) $\mathrm{m}^{-2} \mathrm{~s}^{-1}$. The matched chambers were model PGW 36, manufactured by Conviron Controlled Environments, Ltd (Winnipeg, Manitoba, Canada). The day time temperatures in the chambers were $22{ }^{\circ} \mathrm{C}, 28^{\circ} \mathrm{C}$ and $34^{\circ} \mathrm{C}$, respectively, with night temperatures $3{ }^{\circ} \mathrm{C}$ lower than the day time temperatures; the photoperiod in these chambers was $12 \mathrm{~h}$ illuminated and $12 \mathrm{~h}$ of darkness.

\section{Alignment, phylogenetic analysis and primer design}

Amino acid sequences were aligned using the maximumlikelihood method implemented in ClustalW. A neighborjoining tree was produced from 1000 bootstrap replicates. We designed primers for the FT homologs using Primer 3 software based on the nucleotide sequences identified via BLAST searches as described in the results. The primers used in this work are shown in Supplementary Table 1. 


\section{Tissues sampled, RNA preparation and quantitative RT-PCR for gene expression studies}

For studies of growth temperature and photoperiod, mature whole leaf blades from the third from the most recently matured leaves were sampled. For the study of various plant organs and growth stages, IBA980002 plants were grown for $168 \mathrm{~d}$ to the third tier of flowering with 12-h photoperiod and $28{ }^{\circ} \mathrm{C}$ day temperature, as described for the temperature experiment, and tissues were sampled as follows: Mature leaves were the whole leaf blades from the third most recently matured leaves; immature leaves were leaf blades from expanding folded leaves surrounding the shoot apex; flower buds were unopened flower buds, between 2 and $3 \mathrm{~mm}$ diameter not including pedicel or inflorescence stalk; fibrous roots were obtained from the exposed root ball after removing plastic pots, from which growing white roots between about 1 and $2 \mathrm{~mm}$ were sampled; storage roots $\geq 2 \mathrm{~cm}$ diameter were rinsed free of soil, and blocks of tissue were sampled from the surface extending $1 \mathrm{~cm}$ into the core, including the cambial region; stem samples were from green stem internodes. Tissue was sampled from growth chamber plants during the last hour of illumination and immediately placed in tea bags and immersed into liquid $\mathrm{N}_{2}$. Tissue was ground to powder with mortar and pestle under liquid $\mathrm{N}_{2}$. Total RNA was extracted using a modified CTAB protocol reported by Monger et al. (2001) and quantified by absorption at $260 \mathrm{~nm}$ (NanoDrop ND-1000, Wilmington, DE, USA). Two $\mu \mathrm{g}$ of the total RNA was used for cDNA synthesis. Prior to the synthesis, RNA was treated with $10 \mathrm{U} /$ $\mu \mathrm{L}$ DNase I (Roche) in DNase 1 buffer and incubated at $37{ }^{\circ} \mathrm{C}$ for 30 min to remove any residual genomic DNA. cDNA synthesis was performed by qScript (Quanta) and Superscript III first strand synthesis kits (Invitrogen), following the manufacturer's instructions. Quantitative real-time PCR was performed using PerfeCTa ${ }^{\mathrm{TM}} \mathrm{SYBR}^{\circledR}$ Green FastMix $^{\text {TM }}$ (Quanta) in a Bio-Rad CFX96 ${ }^{\mathrm{TM}}$ Real-Time System, C1000 ${ }^{\mathrm{TM}}$ Thermal Cycler. Primers for cassava 18S RNA and for ubiquitin were used as internal controls (Supplementary Table 1). The real-time quantitative PCR was repeated with three biological replicates, and each sample was assayed in duplicate using primers listed in Supplementary Table 1. Data for the number of PCR cycles to reach the threshold (Ct) were normalized for $18 \mathrm{~S} \mathrm{Ct}$ values in each specimen by subtraction $(\triangle \mathrm{Ct})$. Values were also normalized for each specimen's UBQ Ct value, and the 18S and UBQ normalized $\Delta \mathrm{Ct}$ values were averaged. These $\Delta \mathrm{Ct}$ values were further normalized $(\Delta \Delta \mathrm{Ct})$ against the genotype/treatment with the lowest quantity of each transcript in each batch, generally TMEB419, and interpreted as normalized fold expression $\left(\log _{2}\right)$ assuming a PCR efficiency of 1.0. When the CT values were plotted on this $\log _{2}$ scale, they were normally distributed and subjected to analysis of variance (ANOVA), as described below.

\section{Flowering traits}

In cassava, flowering is associated with fork-type branching which occurs via outgrowth of axillary meristems subtending the shoot apical meristem (Perera et al. 2013). After the first fork, two to four second-tier shoots develop and each of them initiates flowers at their shoot apexes (second-tier flowers). Third and subsequent tiers of flowering develop similarly. Flowering traits were recorded weekly to determine the date of flower or inflorescence appearance.

\section{Statistical analysis}

Gene expression data for tissues and temperature had four biological replicates; for photoperiod, there were two batches (blocks), each with three biological replicates, which were subjected to analysis of variance (ANOVA) using a model for determining effects due to genotype $(\mathrm{G})$, blocks (B), and effects due to interaction of $\mathrm{T} \times \mathrm{G}$. Each trait was analyzed using the linear model in $\mathrm{R}$ (version 3.1.1, R Foundation for Statistical Computing, http://www.r-project.org/. For flowering morphology, the fraction of plants that flowered and the days to flowering were analyzed by the Cox proportional hazard test (Cox 1972).

Author contribution statement $\mathrm{OA}$ and TS designed the experiments; TS obtained the funding; $\mathrm{OA}, \mathrm{PH}$ and TS did the greenhouse and growth chamber work and associated data collection; OA performed the transcript expression analysis; OA, PH and TS analyzed the data; OA and TS prepared the tables and figures and wrote the manuscript.

Acknowledgements This work is part of the Next Generation (NEXTGEN) Cassava project at Cornell University, which is supported by a grant from the Bill \& Melinda Gates Foundation and the Department for International Development of the United Kingdom. We thank Viviane de Abreu for assistance in the greenhouse. We thank IITA and NaCRRI for providing the genotype stocks for these studies.

\section{Compliance with ethical standards}

Conflict of interest The authors declare that they have no conflict of interest.

Data availability The datasets generated during the current study are available from Cassavabase, https://www.cassavabase.org, a website maintained by the Next Generation (NEXTGEN) Cassava Breeding Project. The data may be accessed at ftp://ftp.cassavabase.org/manus cripts/Adeyemo_et_al_2018.zip and are available in accordance with Creative Commons Attribution (CC-BY) license. Cassavabase adheres to the Toronto agreement on prepublication data release. 
OpenAccess This article is distributed under the terms of the Creative Commons Attribution 4.0 International License (http://creativeco mmons.org/licenses/by/4.0/), which permits unrestricted use, distribution, and reproduction in any medium, provided you give appropriate credit to the original author(s) and the source, provide a link to the Creative Commons license, and indicate if changes were made.

\section{References}

Adeyemo O, Kolmos E, Tohme J, Chavariaga P, Fregene M, Davis $S$ (2011) Identification and characterization of the cassava coreclock gene EARLY FLOWERING. Trop Plant Biol 4:117-125

Adeyemo OS, Chavarriaga P, Tohme J, Fregene M, Davis SJ, Setter TL (2017) Overexpression of Arabidopsis FLOWERING LOCUS $\mathrm{T}$ (FT) gene improves floral development in cassava (Manihot esculenta, Crantz). PLoS ONE 12:e0181460

Andres F, Coupland G (2012) The genetic basis of flowering responses to seasonal cues. Nat Rev Genet 13:627-639

Baumann K, Venail J, Berbel A, Domenech MJ, Money T, Conti L, Hanzawa Y, Madueno F, Bradley D (2015) Changing the spatial pattern of TFL1 expression reveals its key role in the shoot meristem in controlling Arabidopsis flowering architecture. J Exp Bot 66:4769-4780

Bredeson JV, Lyons JB, Prochnik SE, Wu GA, Ha CM, Edsinger-Gonzales E, Grimwood J, Schmutz J, Rabbi IY, Egesi C, Nauluvula P, Lebot V, Ndunguru J, Mkamilo G, Bart RS, Setter TL, Gleadow RM, Kulakow P, Ferguson ME, Rounsley S, Rokhsar DS (2016) Sequencing wild and cultivated cassava and related species reveals extensive interspecific hybridization and genetic diversity. Nat Biotechnol 34:562-570

Buckler ES, Holland JB, Bradbury PJ, Acharya CB, Brown PJ, Browne C, Ersoz E, Flint-Garcia S, Garcia A, Glaubitz JC, Goodman MM, Harjes C, Guill K, Kroon DE, Larsson S, Lepak NK, Li H, Mitchell SE, Pressoir G, Peiffer JA, Rosas MO, Rocheford TR, Romay MC, Romero S, Salvo S, Villeda HS, Sofia da Silva H, Sun Q, Tian F, Upadyayula N, Ware D, Yates H, Yu J, Zhang Z, Kresovich S, McMullen MD (2009) The genetic architecture of maize flowering time. Science 325:714-718

Ceballos H, Kawuki RS, Gracen VE, Yencho GC, Hershey CH (2015) Conventional breeding, marker-assisted selection, genomic selection and inbreeding in clonally propagated crops: a case study for cassava. Theor Appl Genet 128:1647-1667

Ceballos H, Jaramillo JJ, Salazar S, Pineda LM, Calle F, Setter T (2017) Induction of flowering in cassava through grafting. J Plant Breed Crop Sci 9:19-29

Chen Q, Payyavula RS, Chen L, Zhang J, Zhang C, Turgeon R (2018) FLOWERING LOCUS T mRNA is synthesized in specialized companion cells in Arabidopsis and Maryland Mammoth tobacco leaf veins. Proc Natl Acad Sci 115:2830-2835

Chica EJ, Albrigo LG (2013) Changes in CsFT transcript abundance at the onset of low-temperature floral induction in sweet orange. J Am Soc Hortic Sci 138:184-189

Cox DR (1972) Regression models and life-tables. J R Stat Soc Ser B (Methodological) 34:187-220

Esumi T, Kitamura Y, Hagihara C, Yamane H, Tao R (2010) Identification of a TFL1 ortholog in Japanese apricot (Prunus mume Sieb. et Zucc.). Sci Hortic (Amsterdam) 125:608-616

FAO (2009) Cassava. In: Food Outlook. Global Market Analysis, vol 2017

Fukuda M, Matsuo S, Kikuchi K, Kawazu Y, Fujiyama R, Honda I (2011) Isolation and functional characterization of the FLOWERING LOCUS T homolog, the LsFT gene, in lettuce. J Plant Physiol 168:1602-1607
Hanzawa Y, Money T, Bradley D (2005) A single amino acid converts a repressor to an activator of flowering. Proc Natl Acad Sci USA 102:7748-7753

Hao X, Chao W, Yang Y, Horvath D (2015) Coordinated expression of FLOWERING LOCUS T and DORMANCY ASSOCIATED MADS-BOX-like genes in leafy spurge. PLoS ONE 10:e0126030

Heffner EL, Sorrells ME, Jannink J-L (2009) Genomic selection for crop improvement. Crop Sci 49:1-12

Hou C-J, Yang C-H (2009) Functional analysis of FT and TFL1 orthologs from orchid (Oncidium gower Ramsey) that regulate the vegetative to reproductive transition. Plant Cell Physiol 50:1544-1557

Jarvis A, Ramirez-Villegas J, Herrera Campo B, Navarro-Racines C (2012) Is cassava the answer to African climate change adaptation? Trop Plant Biol 5:9-29

Jin S, Jung HS, Chung KS, Lee JH, Ahn JH (2015) FLOWERING LOCUS T has higher protein mobility than TWIN SISTER OF FT. J Exp Bot 66:6109-6117

Jung J-H, Domijan M, Klose C, Biswas S, Ezer D, Gao M, Khattak AK, Box MS, Charoensawan V, Cortijo S, Kumar M, Grant A, Locke JCW, Schaefer E, Jaeger KE, Wigge PA (2016) Phytochromes function as thermosensors in Arabidopsis. Science 354:886-889

Leihner D (2002) Agronomy and cropping systems, chapter 6. In: Hillocks RJ, Thresh JM, Bellotti AC (eds) Cassava biology, production and utilization. CABI, Oxford, pp 91-113

Li Y, Huang Y, Bergelson J, Nordborg M, Borevitz JO (2010) Association mapping of local climate-sensitive quantitative trait loci in Arabidopsis thaliana. Proc Natl Acad Sci 107:21199-21204

Li C, Luo L, Fu Q, Niu L, Xu Z-F (2014) Isolation and functional characterization of JcFT, a FLOWERING LOCUS T (FT) homologous gene from the biofuel plant Jatropha curcas. BMC Plant Biol 14:125

Li C, Zhang Y, Zhang K, Guo D, Cui B, Wang X, Huang X (2015) Promoting flowering, lateral shoot outgrowth, leaf development, and flower abscission in tobacco plants overexpressing cotton FLOWERING LOCUS T (FT)-like gene GhFT1. Front Plant Sci 6:454

Li C, Fu Q, Niu L, Luo L, Chen J, Xu Z-F (2017) Three TFL1 homologues regulate floral initiation in the biofuel plant Jatropha curcas. Sci Rep 7:43090

Lifschitz E, Ayre BG, Eshed Y (2014) Florigen and anti-florigen-a systemic mechanism for coordinating growth and termination in flowering plants. Front Plant Sci 5:465

Melzer R (2017) Regulation of flowering time: a splicy business. J Exp Bot 68:5017-5020

Monger WA, Seal S, Cotton S, Foster GD (2001) Identification of different isolates of Cassava brown streak virus and development of a diagnostic test. Plant Pathol 50:768-775

Nakano Y, Higuchi Y, Sumitomo K, Oda A, Hisamatsu T (2015a) Delay of flowering by high temperature in chrysanthemum: heatsensitive time-of-day and heat effects on CsFTL3 and CsAFT gene expression. J Hortic Sci Biotechnol 90:143-149

Nakano Y, Higuchi Y, Yoshida Y, Hisamatsu T (2015b) Environmental responses of the FT/TFL1 gene family and their involvement in flower induction in Fragaria $\times$ ananassa. J Plant Physiol 177:60-66

Nan H, Cao D, Zhang D, Li Y, Lu S, Tang L, Yuan X, Liu B, Kong F (2014) GmFT2a and GmFT5a redundantly and differentially regulate flowering through interaction with and upregulation of the bZIP transcription factor GmFDL19 in soybean. PLoS ONE 9:e97669

Noy-Porat T, Cohen D, Mathew D, Eshel A, Kamenetsky R, Flaishman MA (2013) Turned on by heat: differential expression of FT and LFY-like genes in Narcissus tazetta during floral transition. J Exp Bot 64:3273-3284 
Paton DM (1968) Photo periodic and temperature control of flower initiation in the late pea cultivar Greenfeast Pisum sativum. Austr J Biol Sci 21:609-617

Perera PIP, Quintero M, Dedicova B, Kularatne JDJS, Ceballos H (2013) Comparative morphology, biology and histology of reproductive development in three lines of Manihot esculenta Crantz (Euphorbiaceae: Crotonoideae). AoB Plants 5:46

Pin PA, Nilsson O (2012) The multifaceted roles of FLOWERING LOCUS T in plant development. Plant Cell Environ 35:1742-1755

Pin PA, Benlloch R, Bonnet D, Wremerth-Weich E, Kraft T, Gielen JJL, Nilsson O (2010) An antagonistic pair of FT homologs mediates the control of flowering time in sugar beet. Science 330:1397-1400

Pose D, Verhage L, Ott F, Yant L, Mathieu J, Angenent GC, Immink RGH, Schmid M (2013) Temperature-dependent regulation of flowering by antagonistic FLM variants. Nature 503:414-417

Serrano-Mislata A, Fernández-Nohales P, Doménech MJ, Hanzawa Y, Bradley D, Madueño F (2016) Separate elements of the TERMINAL FLOWER 1 cis-regulatory region integrate pathways to control flowering time and shoot meristem identity. Development 143:3315-3327

Tao Y-B, Luo L, He L-L, Ni J, Xu Z-F (2014) A promoter analysis of MOTHER OF FT AND TFL1 1 (JcMFT1), a seed-preferential gene from the biofuel plant Jatropha curcas. J Plant Res 127:513-524
Taoka K, Ohki I, Tsuji H, Kojima C, Shimamoto K (2013) Structure and function of florigen and the receptor complex. Trends Plant Sci 18:287-294

Thines BC, Youn Y, Duarte MI, Harmon FG (2014) The time of day effects of warm temperature on flowering time involve PIF4 and PIF5. J Exp Bot 65:1141-1151

Turck F, Fornara F, Coupland G (2008) Regulation and identity of florigen: FLOWERING LOCUS T moves center stage. Annu Rev Plant Biol 59:573-594

Wang Z, Zhou Z, Liu Y, Liu T, Li Q, Ji Y, Li C, Fang C, Wang M, Wu M, Shen Y, Tang T, Ma J, Tian Z (2015) Functional evolution of phosphatidylethanolamine binding proteins in soybean and Arabidopsis. Plant Cell 27:323-336

Wickland DP, Hanzawa Y (2015) The FLOWERING LOCUS T/ TERMINAL FLOWER 1 gene family: functional evolution and molecular mechanisms. Mol Plant 8:983-997

Wolfe MD, Del Carpio DP, Alabi O, Ezenwaka LC, Ikeogu UN, Kayondo IS, Lozano R, Okeke UG, Ozimati AA, Williams E, Egesi C, Kawuki RS, Kulakow P, Rabbi IY, Jannink J-L (2017) Prospects for genomic selection in cassava breeding. Plant Genome 10:3

Yan W, Wallace DH (1996) A model of photoperiod $\times$ temperature interaction effects on plant development. Crit Rev Plant Sci 15:63-96

Zeevaart JAD (2008) Leaf-produced floral signals. Curr Opin Plant Biol 11:541-547 